ISSN electrónico: 2172-9077

https://doi.org/10.14201/fjc201715219223

\title{
TERRORISMO Y COMUNICACIÓN: LA NECESIDAD DE DESPERTAR EL VALOR CRÍTICO
}

\section{Terrorism and Communication: The Need to Awaken the Critical Value}

Dra. Montserrat JURADO MARTÍN

Profesor Ayudante Doctor, Universidad Miguel Hernández de Elche, España

E-mail:mjurado@umh.es

(iD) orcid.org/0000-0002-0918-2328

Fecha de recepción de la reseña: 02/07/2017

Fecha de aceptación definitiva: 10/07/2017

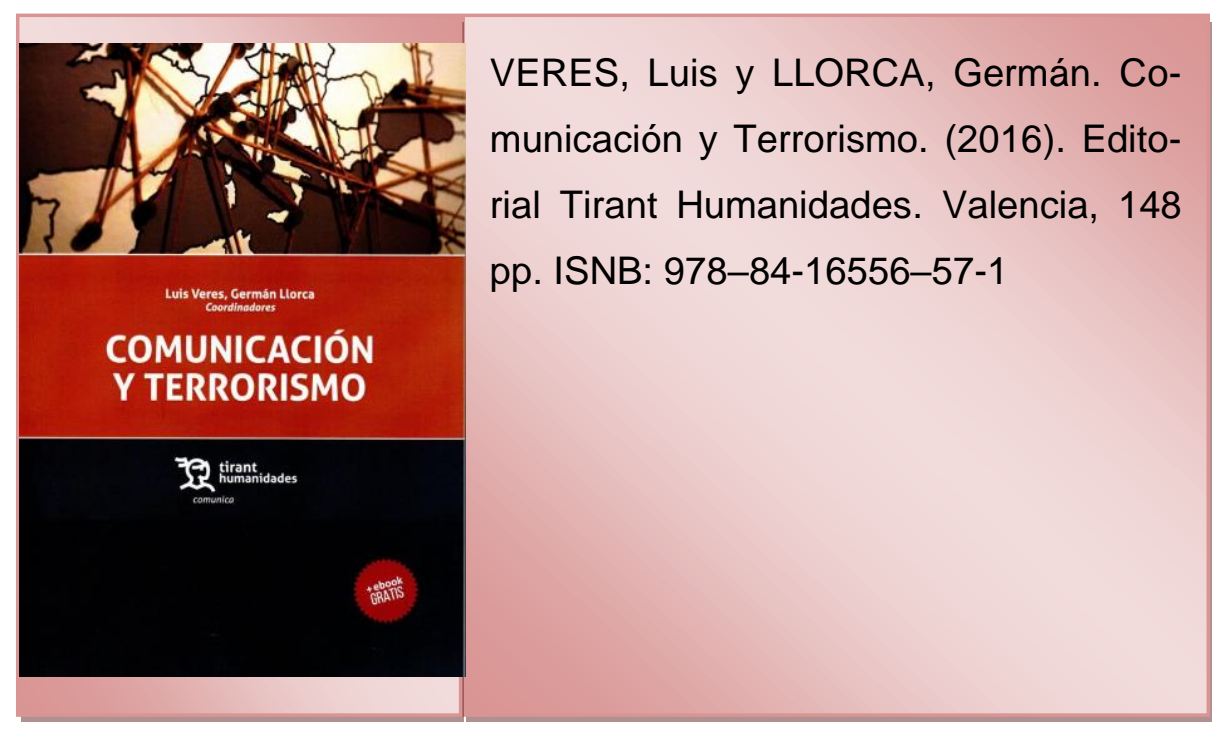

\section{EL EJERCICIO DE PENSAR}

Inviten a las personas de su entorno a la reflexión, al diálogo complejo, a la crítica meditada de cualquier tema de actualidad. Si encuentran a alguien será más interesante si además sabe del tema y su formación sobre este lo es por inquietud personal y no por 'de’formación profesional. Más difícil si 
sus fuentes de información no son exclusivamente las noticias de los medios de comunicación y sus argumentos van más allá del fast food diario.

Esta es la reflexión a la que nos invita Comunicación y Terrorismo. Un libro que no agota toda la temática que propone porque su fin no es este, sino potenciar el valor y la necesidad de reflexión del tema que aborda: el tratamiento que los medios de comunicación y otros soportes audiovisuales difunden sobre el terrorismo.

Las tragedias asociadas al terrorismo no son tratadas de la misma manera por los medios de comunicación (Rodrigo, 1991). En función de quién las protagonice o la nacionalidad de los fallecidos, los medios otorgan una importancia relativa y cuestionable. «Es menos espectacular hablar de 1.100 muertos en un país del Tercer Mundo, que de tres en el 'primer país' del Primer Mundo», explica Llorca (2016, pp. 9-22), coordinador del libro y autor del primer capítulo que viene a servir de prólogo. Más sensibilidad despiertan los intereses ocultos, o no tan ocultos, de empresas que nada tienen que ver con la política pero que los usan en su beneficio. $\mathrm{Y}$ al hablar de empresas se deben incluir también las empresas de producción periodística y los intereses que puedan tener en la difusión de los temas relativos al terrorismo (Lempen, 1980, p. 72), algunos autores hablan incluso de simbiosis (Soria, 1990) y necesidad mutua (Marletti, 1979).

Como nos enseñaban los profesores en las aulas, solo existe lo que los medios difunden, mientras que el resto de temas acontecidos 'nunca ocurrieron'. Los temas de la agenda están fijados (Mc Combs y Valenzuela, 2007) y no son cuestionados por los redactores, hoy en día más preocupados por mantener su trabajo (Ufarte, 2011) que por la búsqueda de los intereses reales que hay detrás de los productos que crean y difunden.

«Pensar cansa y es preferible la comodidad de un cliché mil veces repetido que realizar un esfuerzo intelectual», afirma Llorca (2016, p. 15). Así se podría concretar el objetivo primero que pretende cubrir el libro que aquí se reseña. Y para su logro se han incluido investigaciones de varios autores que destacan por su variedad y diferentes puntos de vista para llegar a la misma conclusión: desde los medios de comunicación y las redes sociales, el cine de ficción, el documental, la fotografía y el libro: la necesidad de despertar el valor crítico. La comunicación sobre los temas de terrorismo es parcial e incompleta.

\section{SIETE EJEMPLOS CON UN MISMO FIN}

El poder de la Yihad es cada vez mayor porque en la elaboración de sus productos comunicativos emplea los mismos recursos y técnicas que las empleadas por los países del Primer Mundo o el poder. Sánchez Castillo (2016, pp. 23-44) invita a la reflexión desde este ángulo: las posibilidades de la red y su interacción lector-usuario en el terrorismo islámico actual. Valora la importancia de sus narrativas para construir ideas, financiar sus acciones, retener y captar nuevos miembros.

El autor desarrolla un exhaustivo trabajo de análisis de productos audiovisuales difundidos en internet y creados por ISIS como parte de su campaña para dar a conocer sus logros. Demuestra que el sistema de producción, edición y guionización es similar al estilo de las películas de Hollywood y esto les ha otorgado credibilidad, influyendo fundamentalmente en la gente joven. Un tema que no se agota en el capítulo ISIS y la persuasión narrativa en la Yibad 3.0 y que anima a la lectura de nuevos trabajos del autor.

El fenómeno del terrorismo es, sin lugar a dudas, un tema inagotable para la industria cinematográfica. Figueroa y Browne (2016, pp. 45-56) retoman el testigo con su capítulo titulado Terrorismo, pánico y locura en los tráilers de Hollywood. Negación, apertura y explotación después del 11-S. Se trata de un 
arriesgado estudio que, con quizás escaso material, concluye que tras el atentado del 11-S se pueden concretar tres periodos en la producción cinematográfica de la industria norteamericana en relación a este acontecimiento. Los denomina: negación, apertura y explotación. Todo el estudio se centra en el análisis de 6 tráilers.

El estudio es interesante ya que retoma el clásico tema de que los norteamericanos son 'los buenos' y el resto del mundo, 'los malos', ya provengan de Oriente, Asia o América Latina y del contexto histórico en el que se propongan las producciones. La hipótesis es interesante y acotada, pero sus conclusiones quizás resultan ambiciosas para el material objeto de estudio, ya que deja fuera otras grandes producciones de países Occidentales o alternativas menos comerciales. Quizás ahí está su diamante en bruto: en el logro en despertar en el lector el interés por todo lo que rodea al tema y que no se menciona porque tampoco es objeto de estudio, es decir, logra hacernos reflexionar, buscar el elemento crítico.

El cine sigue siendo el soporte comunicativo sobre el que se desarrolla el capítulo titulado Violencia y estética terrorista en el cine de la postdictadura. Silva (2016, pp. 57-65) recuerda que el terrorismo no evidencia exclusivamente la violencia, sino que es la herramienta de la que se valen las sociedades para imponer criterios políticos, culturales, económicos y sociales.

Con ejemplos cinematográficos seleccionados describe el terrorismo de denuncia frente al imperialismo del Tercer Mundo, y más concretamente norteamericano, concretado primero en Cuba, después Nicaragua y finalmente en Centroamérica. Con conocimiento de causa, estudio pormenorizado de las películas analizadas y su contexto histórico y mención a la bibliografía pertinente, el capítulo logra satisfacer la curiosidad y el interés por un tema menos mediático que el cine comercial 'made in USA'. Concluye destacando el paso de las dictaduras cívico-militares de los años 60 y 70 al estado de excepción posdictatorial, con el empleo de la estética terrorista y posterrorista como genocidio tecnoburocrático (Silva, 2012, p. 64).

La mirada centrada en el ejemplo más pequeño para después llevarla a la generalización más amplia como modelo de manifestación del terrorismo es, sin lugar a dudas, el capítulo titulado Terrorismo y criminalización: los mapuche y el género documental. Su autor, Vives (2016, pp. 67-81) y también uno de los coordinadores de esta publicación, nos descubre otro enfoque del terrorismo, más soterrado e igualmente dañino. Aquí no hay 'buenos' y 'malos', aquí hay 'lo nuevo' y 'lo viejo': el indio es signo de atraso y todo lo que viene del exterior es lo moderno, donde se deben de encaminar las jóvenes repúblicas latinoamericanas (Vives, 2016, p. 68).

«Los mapuche son una minoría étnica que habita en una ancha franja en el sur de Chile» explica su autor y relata cómo poco a poco han sufrido la reducción de sus tierras por entidades con intereses económicos, que en muchos casos también son los dueños de las grandes empresas de comunicación de la zona. De este modo, los temas de interés para el pueblo mapuche no encuentran espacio de difusión.

El terrorismo y la violencia pueden tomar diversas formas. Y este es el enfoque que muestra este capítulo que se esfuerza en hacer patente, quizás resultando forzado o artificial sin necesidad, el paralelismo entre el ocultamiento del terrorismo mapuche y la respuesta a la invisibilización del problema palestino subyacente en el atentado del 11-S y otros ejemplos de conflictos silenciados. Como estudio de caso resulta interesante toda la revisión audiovisual documental del tema mapuche para reconocer finalmente que no se debe denominar terrorismo al delito común y al crimen, «es un error evidente que responde a una estrategia de manipulación semántica que en definitiva tiene como objeto la criminalización del pueblo mapuche» (Vives, 2016, p. 77). 
En un libro sobre terrorismo y comunicación se habría echado de menos la ausencia de un capítulo sobre el escenario mexicano y el narcotráfico. La investigadora Díaz Cerveró (2016, pp. 83-103), prudentemente, avanza que se trata de una selección de películas de un universo muy amplio sobre la temática. El capítulo Terrorismo y narcotráfico en la gran pantalla: los casos de ETA en España y el narcotráfico en México tiene por objeto establecer una compleja relación entre ambos escenarios, concretando un listado de semejanzas y diferencias con objeto de entender los posibles paralelismos en los efectos que causan las películas sobre esta temática en el público mexicano y español. La propuesta es algo abstracta, como pudiera serlo el arte contemporáneo, pero despierta la curiosidad, como pueda hacerlo el Guernica de Picasso.

El estudio que hace es amplio y arriesgado tanto en el tema vasco como en el mexicano y evidencia el punto de vista de la autora, una frescura que muchas veces se echa en falta en textos de grandes investigadores que los son sin dejar carne en el asador. Invita a la crítica y no deja indiferente. «La proyección de violencia no tiene por qué generar más violencia, pero esa premisa solo es válida si tenemos en cuenta la mera trasmisión de contenidos en un sistema comunicativo carente de contexto» (Díaz Cerveró, 2016, p. 101).

La fotografía, como soporte de comunicación en el medio impreso, encuentra su espacio en el capítulo Terrorismo y Fotografía. Lleva a cabo un estudio de las imágenes publicadas en los diarios $A B C$, El Diario Vasco y El País en las décadas de 1970, 1980 y 1990 que acompañaban a atentados perpetrados por ETA. García-Lafuente (2016, pp. 106-138) plantea como hipótesis de partida la evolución del tratamiento informativo, sin formular realmente dicha hipótesis y que rescata prácticamente al final (2016, p. 136) explicando que «una de las hipótesis de partida pretende conocer si la cobertura informativa gráfica depende de la condición social de la víctima, la ideología del periódico o el contexto histórico» y concluye que «la cobertura va en relación al número de muertos, el contexto político, las muertes de niños, la repercusión pública y la actualidad que rodea al atentado».

El estudio es interesante, pero deja lagunas al lector indefenso para formar su criterio. No obstante, el análisis de contenido resulta de interés en relación al tratamiento que los medios impresos dan a estos temas y siempre es de obligada mención el esfuerzo por esta elección de esta minuciosa metodología.

Finalmente, también se ha encontrado un espacio para otro de los soportes comunicativos más emblemáticos: el libro. Solovieva (2016, pp. 139-148) expone un interesante trabajo sobre los conceptos 'terror' y 'terrorismo' y cómo están asociados a agentes sociales opuestos: el primero a las clases gubernamentales opresoras y, el segundo, a una reacción de la clase oprimida, todo ello en el contexto ruso. Bajo el título El terrorista como autor y protagonista de la novela rusa, analiza obras autobiográficas que denuncian los hechos de terror o terrorismo y daban a conocer delitos que los medios de comunicación no trasmitían.

\section{VALIENTES Y CON VALOR CRÍTICO}

Esta compacta obra «indaga sobre los distintos escenarios en los que se mueve el terrorismo moderno con algunas de sus contradicciones y condicionantes». Sin lugar a dudas es valiente publicar un libro que bajo el título Comunicación y Terrorismo abarca soportes de difusión de la comunicación tan diferentes: cine, redes sociales, libros, fotografía o periódicos, pero no agota ninguno de ellos y apenas supone un sabroso aperitivo en las áreas que recoge. Se echa de menos quizás un subtítulo que le diera un enfoque más concreto, que concretara lo que sin duda debe acompañar a esta interesante propuesta: una serie de nuevas publicaciones que le dieran continuidad. No estaría de más agotar en cada una 
de ellas los espacios de difusión del tipo Comunicación y Terrorismo: en el cine; en la fotografía periodística, en la literatura, en el tratamiento de agentes terroristas, etc. Dado así, se puede perder durante el camino de la lectura el común denominador que los une.

En definitiva, si la mirada solo se detiene en el dedo y no ve el infinito al que apunta difícilmente puede verse el contexto. No hay valor crítico en los titulares, ni siquiera en los textos, ni en la selección de los temas. Hay que ver más allá, leer en abundancia, hacer todas las preguntas. Si la información es poder, ese poder también está en las manos del lector, de todos los lectores. Este libro es sin duda un primer paso valiente y de obligatoria lectura.

\section{BIBLIOGRAFÍA}

Lempen, B. (1980). Information et pouvoir. Lausana: L’Âge d'Homme.

Marletti, C. (1979). El terrorismo moderno como estrategia de comunicación. Algunas consideraciones a partir del caso italiano. En J. Vidal Beyeyto (ed.), Alternativas populares a las comunicaciones de masa. Madrid: Centro de Investigaciones Sociológicas.

Mc Combs, M. y Valenzuela, S. (2007). The Agenda-Setting Theory. Cuadernos de Información, 20, 44-50. Rodrigo Alsina, M (1991). Los medios de comunicación ante el terrorismo. Editorial Icaria.

Soria, C. (1980). Ethos informativo y terrorismo. Revista General de Legislación y Jurisprudencia, enero.

Ufarte Ruiz, M. J. (2011). El periodista acosado: entre la precariedad laboral y el mobbing. Tesis doctoral. Recuperado de: http://fondosdigitales.us.es/tesis/tesis/1579/el-periodista-acosado-entrela-precariedad-laboral-y-el-mobbing-un-estudio-de-caso-la-precariedad-de-los-periodistasalmerienses-en-la-prensa-escrita/\#description

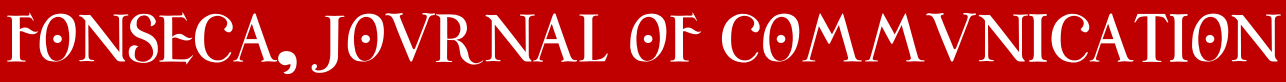

